REVIEW

\title{
Terminal care in paediatrics: where we are now
}

\author{
F Hutchinson, N King, R D W Hain
}

Postgrad Med J 2003;79:566-568

As in adults, palliative care in children is a comprehensive multidisciplinary approach to care that seeks to enhance the life of children and families living with life limiting conditions. It involves a holistic approach embracing symptom management, psychosocial/spiritual care, and bereavement support.

See end of article for authors' affiliations ....................

Correspondence to: Dr Richard Hain, Department of Child Health, Llandough Hospital, Cardiff CF64 2XX, UK;

HainRD@Cardiff.ac.uk

Submitted

10 September 2002

Accepted

19 November 2002 t is nearly 40 years since palliative medicine began to emerge as a specialty in adult medicine. It seems to have taken much longer for paediatricians to recognise the distinct needs of some children for specialist palliative care.

Perhaps this is because the philosophy of paediatrics itself embodies some of what palliative medicine sought to recapture in adult medicine. Like palliative medicine, paediatrics has always recognised the need to see the patient in the wider context of home and family, to address issues beyond the physical, and to work alongside other professions to achieve these things.

Nevertheless, children with life limiting conditions do not yet have access to the same specialist expertise in palliative care that adults can now expect. Like all paediatric specialties, palliative care in children cannot simply be imported. The more dimensions one examines, the less children resemble adults. Paediatric palliative care must grow from the practice and experience of those trained to care for children. We have, however, a great deal to learn from our "adult" colleagues who have, after all, been perfecting palliation for many years.

As in adults, palliative care in children is a comprehensive multidisciplinary approach to care that seeks to enhance the life of children and families living with life limiting conditions. It involves a holistic approach embracing symptom management, psychosocial/spiritual care, and bereavement support.

Palliative care is not simply a matter of withdrawing active treatment. Some palliative interventions may themselves be quite active (for example, where appropriate, non-invasive nocturnal positive pressure ventilation for children with Duchenne muscular dystrophy). A palliative approach' does, however, mean proceeding with an intervention only when its benefit outweighs the burden it imposes, not only on the patient but also on the entire family.

Terminal care is part of palliative care and takes place during the last few weeks of the child's life. The aim is to prepare both the child and family for death psychologically and spiritually, at the same time as managing the symptoms of the illness or condition to make the child as comfortable as possible. Palliative care, in contrast, may have a role throughout the life of some children. For them, referral to specialist palliative care services in the last few weeks can make management less than ideal.

\section{NATURE OF TERMINAL CARE IN CHILDREN Life limiting illness in paediatrics}

Children die from a variety of illnesses not seen in adulthood. Adult palliative care has traditionally concentrated on patients dying from cancer, and paediatricians can learn a lot from adult colleagues in dealing with difficult symptom management in children with malignant conditions.

In contrast, cancer is only one among many life limiting conditions in childhood. Children with non-malignant life limiting conditions may survive years or even decades with heavy and complex medical needs, before a premature death. Diseases may be specific to children and be individually very rare (for example, Hunter's disease) or, more rarely, diseases seen in adults presenting early such as Huntington's disease. The diseases may be genetic and thus there may be more than one affected member in a family.

Some children with these conditions now live much longer than in the past, even surviving into adulthood-particularly those with cystic fibrosis and some congenital heart disease. New services for these children have been slow to develop.

In children with cancer, the dying phase is often relatively short and can pursue a predictable course. In contrast, in other life limiting conditions there may be several episodes during which death seems imminent, only for a child to recover for a while until the next episode. Parents and staff live with continuing uncertainty.

\section{Epidemiology}

The prevalence of children with life limiting illnesses is very significant. It was estimated by the Royal College of Paediatrics and Child Health (RCPCH) to be one per $1000^{1}$ and even this may be an underestimate. ${ }^{2}$ The figures are important when planning palliative and terminal care services for these children, but their interpretation is complicated by the fact that they have not previously been considered as a specific group, and no database has been established. One recommendation of the $\mathrm{RCPCH} /$ Association for Children with Life-Threatening or Terminal Conditions (ACT) report is that this be addressed.

Abbreviations: ACT, Association for Children with LifeThreatening or Terminal Conditions; RCPCH, Royal College of Paediatrics and Child Health 


\section{Delivery of terminal care}

The needs of children in the palliative phase are quite distinct from those of adults. Rather than bringing the child into a hospice, the work done in paediatric palliative care suggests that most parents want their child to die at home, ${ }^{3}$ and the challenge is to provide good quality terminal care at home. For others, children's hospices do potentially offer an acceptable alternative "home from home", which is often not considered or fully explored.

Adults in the terminal phase are often referred and care handed over from "active treatment" consultants to the palliative medicine team. In contrast, paediatric consultants typically wish to continue their involvement with a family right to the end. Those with skills in palliative care will work alongside other paediatric consultants making up a new "virtual team" if requested to so. This has many advantages: skills and knowledge are pooled, some of the professional team remain familiar to the family and it does not seem to the family that the referring team has given up on them. Other paediatric consultants may not have all the appropriate skills and up-to-date knowledge to do this alone and there is a growing recognition of the need for paediatric palliative care consultants who can also help work across the hospital/community boundary, bringing together existing services and skills.

In the UK there are several different models of delivering terminal care to children, which have developed separately, but are now increasingly working together. ${ }^{5}$

- Outreach model—a disease based approach, comprising paediatric outreach nurses liaising with a specialist paediatric consultant. Children in the terminal phase are usually nursed at home with their families. This model is typified by paediatric oncology services, and increasingly emulated (for example by neonatal and respiratory teams).

- Children's hospice movement-this, like the adult movement 10 years before, developed largely independently of paediatricians. Most are paid for by charity, and run by nurses, with medical support from general practitioners. ${ }^{5}$ Unlike adult hospices, most focus on providing high quality specialist respite, rather than terminal care.

- Community nursing teams-these liaise where necessary with community paediatric consultants. These teams, such as the Lifetime Service in Bath, ${ }^{6}$ can have a particular role in the protracted terminal phase of many non-oncology life limiting conditions.

Bringing together elements of all these models, increasing numbers of paediatricians are developing palliative care as their main or only clinical interest. Such consultants can bring to the terminal care of a child support for all those providing terminal care, working across the hospital/community divide to coordinate and help provide optimal management in the terminal phase. Where there are no specialist palliative care paediatricians, adult palliative care consultants can be very supportive advising on difficult symptom management, particularly in paediatric oncology. ${ }^{7}$

\section{CHALLENGES TO ADEQUATE PROVISION OF TERMINAL CARE FOR CHILDREN}

The nature of terminal care in paediatrics throws up particular challenges.

\section{Environment}

Children with life limiting conditions have complex needs, which need to be addressed in numerous clinical areas, particularly home, hospital, school, and often children's hospice. Services are currently patchy and in places poorly coordinated. ${ }^{1356}$ Funding has been difficult.
Care at home in the terminal phase is ideal for most but not all families, and is not always possible often due to lack of resources and planning. Where they are available, children's hospices can provide a high quality alternative to home as part of a package of terminal care.

Specialist paediatrics typically takes place in an acute hospital environment where the emphasis is on cure where possible. This environment is much less conducive to management in the terminal phase. Dying children and their families may need considerable investments of time, not only in careful assessment and review of their physical symptoms, but in identifying and exploring emotional and spiritual issues. The emphasis on finding a cure is reflected in research and education priorities; one difficulty in providing optimal terminal care is the very narrow evidence base available.

\section{Shortage of medical paediatric professionals skilled in terminal care}

Currently there are only four paediatric palliative care consultants in the UK, though more are planned. There are a number of oncologists who are interested in palliative care for all children and not just those with cancer, as well as other hospital specialists who are becoming increasing interested in developing skills. A number of community consultants have developed skills in managing terminal care. Some general practitioners attached to hospices have considerable skills in paediatric terminal care.

Until recently many of these children with rare nonmalignant illnesses have been considered as separate groups. ${ }^{6}$ Services, professional education, and research have been slow to develop for these children in the terminal phase. Hospices have provided (and continue to provide) invaluable and cost effective respite care.

\section{Role of hospices}

Children's hospices are typically purpose built to provide specialist respite care in an environment that, as far as is possible, feels like home. Medical support is usually from general practitioners. Clearly there is an overlap between respite and terminal care. And some children's hospice doctors, most of whom come from a general practice background rather than paediatrics or palliative care, have developed considerable expertise in terminal care. Most children's hospices offer specialist respite care rather than terminal care. This may change as paediatricians are increasingly able to support their colleagues working in children's hospices. It may be that children's hospices will become much more significant providers of terminal care in the future for those families who do not want their child to die at home.

\section{Adolescents and young adults}

The needs of adolescents and young adults with life limiting conditions (malignant or non-malignant) are quite distinct either from those of children or of adults. Again, it would be ideal if the terminal phase could always be managed at home. In practice, this is often difficult for emotional and psychological reasons as well as purely practical ones. Adult hospices or acute hospital wards are not usually appropriate environments. Many young people have had occasional respite care from the children's hospice for many years but most children's hospices cannot easily extend their services into adulthood.

There is room for the development of transitional services for such children and young people. Douglas House, an innovative "respice" for this purpose is being built in Oxford, and many adult palliative care physicians as well as paediatricians are developing a particular interest in the care of adolescents.

The terminal phase is often characterised by the intense demands it makes on medical and nursing staff as well as other therapists involved. Although providing a 24 hour terminal care service in the home should be the gold 
standard, it is clearly not always possible to provide it. In the past adult community nursing has been a godsend when there has been no community paediatric team or 24 hour cover. However adult nurses in the community are increasingly reluctant to work with children, therefore making cover even more patchy. Community paediatric nurses may not have the skills or training and need back-up from consultants with relevant experience in the terminal phase.

\section{Research and training}

Because the numbers of children needing terminal care are small in comparison with adults, they have only recently been considered as a separate group and research in the field has been slow to develop. Much of what has been done in practice has been anecdotal or extrapolated from adult work. Increasingly, research is being conceived and designed specifically to examine issues of terminal care in children.

\section{Training for professionals working in paediatric palliative care is in its infancy ${ }^{\prime}$}

Many paediatric doctors are inexperienced and poorly educated in the management of pain, the use of opiates, symptom management, and issues around terminal care and this needs to addressed by those working in paediatric palliative care. There is a dedicated specialist registrar programme at Great Ormond Street for paediatricians wishing to become consultants in paediatric palliative care, and a second is planned in Cardiff. There is also a distance learning diploma in paediatric palliative medicine, based at Cardiff University.

\section{RECOMMENDATIONS}

Paediatric palliative care is becoming a specialty in its own right, now recognised by the RCPCH and Royal College of Nursing. In 1995 a joint working party of ACT (www.act. org.uk) and the RCPCH set out to consider the provision of children's palliative care services in the UK and make recommendations. ${ }^{1}$ In 1997 they produced A Guide To The Development Of Children's Palliative Care Services and made a series of recommendations which included that these children and families need flexible but coordinated care with the use of key workers.

Each district should have a senior paediatric professional to coordinate services a tertiary network of children's palliative care specialists should be developed as a resource for local professionals and a basis for advice, training, and research.

There is now a British Society of Paediatric Palliative Medicine for doctors working in or developing terminal care in children. Most are paediatricians or children's hospice doctors, but there are also adult palliative medicine physicians.

\section{SPECIALIST PALLIATIVE CARE PAEDIATRICIANS: AN EMERGING SOLUTION}

There are now three consultants in paediatric palliative care in the UK and more planned. The roles of the paediatric palliative care consultant in terminal care include:

- Taking an "overview" and developing district wide strategies to include all children with terminal care needs, so that all children and families have choices and not just those who belong to a disease specific group such as cancer. The aim is to bring together existing services, then to identify and try to fill gaps in provision.

- Expertise in symptom management, psychological support, difficult communication, and bereavement across a wide range of life limiting conditions.

- Networking and pooling knowledge (for example, conferences, websites, PaedPalLit: www.ack.org.uk) in a way that will promote further knowledge, better symptom management, better services, education, and research in this new specialty. Such support is not limited to medicine, but includes others providing aspects of terminal care such as chaplains, charitable organisations (especially children's hospices), social workers, teachers, etc.

- Professional facilitation in ethical issues, both in the individual patient ("Can we abandon artificial feeding?") and in national and international strategies.

- Supporting colleagues. Reassurance and support, such as "debriefing", is important for staff who may have had little contact with dying children and find it very distressing, and is also important for staff who have had prior involvement with dying children but still need support in these very difficult situations.

- Education, audit, and research specifically in terminal care issues.

\section{SUMMARY}

The challenges of providing quality terminal care to children are those of developing good palliative medicine at any stage of a child's illness. The spectrum of life limiting conditions in childhood is very wide, encompassing both malignant and non-malignant disease. The terminal phase can vary from predictable and rapid deterioration on the one hand to fluctuation, uncertainty, and a lingering death on the other. Some children may have to live through many apparently terminal phases.

Children need to be with their families, but they may also need skilled medical and nursing support that can be difficult to provide at home. Many models have evolved, often independently, to try and meet these conflicting needs. They include hospital or community outreach teams that deliver specialist care into the home, and children's hospices that offer a "home from home" which can accommodate child and family and provide much needed respite in the terminal phase.

The needs of children with life limiting conditions are complex. No single model can offer the whole package that they and their families need in the terminal phase. We need not only to develop and apply new techniques in practical, evidence based symptom control, but also to make the most of the skills of others by learning to work in collaboration with different models. This combination of skills in innovation, application, collaboration, and coordination defines the role of the specialist in paediatric palliative medicine.

\section{Authors' affiliations \\ F Hutchinson, Hospital for Sick Children, Great Ormond Street, London N King, Heart of Kent Hospice, Aylesford, Kent \\ R D W Hain, University of Wales College of Medicine, Department of Child Health, Llandough Hospital, Cardiff}

\section{REFERENCES}

1 Baum D, Curtis H, Elston S, et al. A guide to the development of children's palliative care services. 1st Ed. Bristol and London: Association for Children with Life-Threatening or Terminal Conditions/Royal College of Paediatrics and Child Health, 1997.

2 Lenton S, Stallard P, Lewis M, et al. Prevalence and morbidity associated with non-malignant, life-threatening conditions in childhood. Child Care Health Dev 2001;27:389-98.

3 Hynson JL, Sawyer SM. Paediatric palliative care: distinctive needs and emerging issues. J Paediatr Child Health 2001;37:323-5.

4 Goldman A. Care of the dying child (revised). In: Goldman A, ed. Care of the dying child. New York: Oxford University Press, 1998:93-106.

5 Hain RDW. The view from a bridge. European Journal of Palliative Care 2002;9:75-7.

6 Lewis $M$. The Lifetime Service: a model for children with life-threatening illnesses and their families. Paediatric Nursing 1999;11:21-3.

7 McQuillan R, Finlay I. Facilitating the care of terminally III children. J Pain Symptom Manage 1996;12:320-4. 